\title{
STUDY OF MULTI-ZONE THERMODYNAMIC MODEL DIRECT-INJECTION COMPRESSION IGNITION ENGINES
}

\author{
Haydar M. Razoqe ${ }^{1}$ \\ hyder_mohee@yahoo.com
}

\author{
Mahmoud A. Mashkour ${ }^{2}$ \\ 20087@uotechnology.edu.iq
}

1 Ministry of science and technology

2 Mechanical engineering Department, University of Technology, al sinaa st., baghdad, 10066, Iraq

\begin{abstract}
The present research investigated multi-zone single-cylinder four-stroke direct-injection model. The model simulates closed cycle processes and describes the combustion behavior by employing thermodynamic equations of a penetration spray theories. The model has been coded on the base of the programming tools of Matlab software. In this simulation model, the combustion events is divided into five zones, in order to determine the amount of fuel, access air, and amount of products in each zone. The simulation model, produced in this work, provides a more accurate framework for zero dimensional model by introducing physical zones within the model that correspond to the combustion structures in the engine. Comparison the results of the simulation model with other methods in the published researches shows that the behavior of engine parameters with theoretical and experimental earlier works has a good agreement. From the simulation model results can be concluded that, there is a change in the limits of the combustion zones with changing engine speed, amount of injected fuel, intake air pressure, and temperature, especially in the rich premixed burn zone.
\end{abstract}

Keywords: multi zone model, spray penetration jet, direct injection compression ignition engine modeling, Matlab,

$$
\text { دراسة نموذج المناطق المتعدة الثرموديناميكي لمحركات الاشتعال بالضغط ذات الحقن }
$$

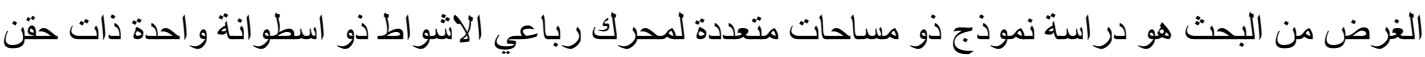

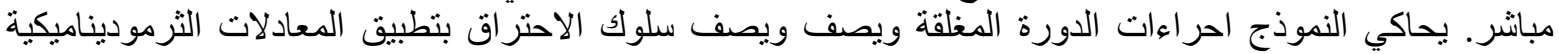

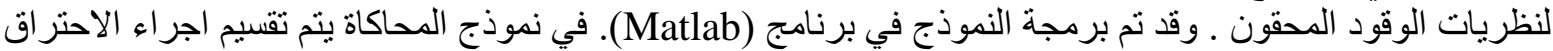

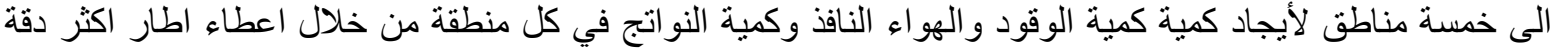

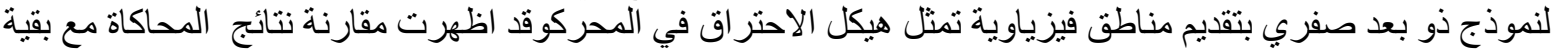

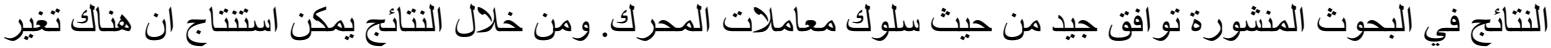

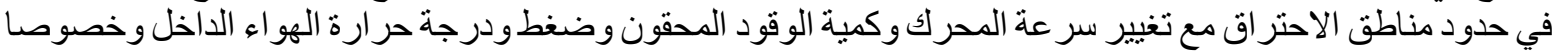
منطقة الاحتر اق مسبقة الخاط. 
NOMENCLTURE

Latin Symbols

BSFC

a

$A F_{s}$

$A_{\text {inj }}$

$A_{\text {PF }}$

B

$b_{l}, k_{1}$

$B_{e}$

$C_{a}$

cetan

$c_{d}$

$c_{p_{\text {nir }}}$

$c_{p \text { fuel }}$

$C_{\text {p.prod }}$

$d_{\text {orifice }}$

$\operatorname{dur}_{C A}$

$\mathrm{E}$

Ea

$H_{\text {air }}$

$h_{f g}$

$H_{\text {fuel }}$

holes

$h_{p}$

$H_{\text {prod }}$

$h_{r}$

$h_{\text {vap }}$

$H_{x}$

$L$

11

$L_{L}$

$L_{S}$

$\widetilde{L}$

$m_{a_{c s t}}$

$m_{a_{1}}$

$\dot{m}_{C A}$

$\dot{m}_{f}$

$m_{f_{z}}$

$m_{f_{2 i g n}}$

$m_{f_{1}}$

$m_{\text {prod }}$

$M W_{f}$

Latin Symbols

$m_{x}$

\section{Description}

brake specific fuel consumption $(\mathrm{kg} / \mathrm{kWh})$

Crankshaft Radius (m)

Stoichiometric Air to fuel ratio

Orifice Area $\left(\mathrm{m}^{2}\right)$

Pre-exponential factor

Cylinder Bore (m)

Linear Regression Parameters

Energy Ratio

Area Contraction Coefficient

Cetan number

Area-Contraction Coefficient

Air Specific Heat (kJ/kg.k)

Fuel Specific Heat (kJ/kg.k)

Products Specific Heat (kJ/kg.k)

Orifice Diameter (m)

Injection Duration (degree)

Energy (kJ)

Active Energy (kJ)

Air Enthalpy $(\mathrm{kJ})$

Fuel Latent Heat (kJ/kg)

Fuel Enthalpy (kJ)

Number of holes in injector

Specific Enthalpy of Products $(\mathrm{kJ} / \mathrm{kg})$

Products Enthalpy (kJ/kg)

Specific Enthalpy of reactants $(\mathrm{kJ} / \mathrm{kg})$

Fuel Latent Heat $(\mathrm{kJ} / \mathrm{kg})$

Output Enthalpy of Control Volume at arbitrary Location (kJ)

Liquid Length $(\mathrm{mm})$

Connected Rod (m)

Liquid length (mm)

Spray Length (mm)

Normalized factor

Consumed air in zone\#2 $(\mathrm{kg})$

Air Mass in zone\#1 (kg)

Fuel flow rate (kmole/deg)

Fuel flow rate (kmole/s)

Unburned Fuel Mass (kg)

Amount of Vapor at Ignition Delay Time (kg)

Fuel Mass in Zone\#1 (kg)

Product Mass (kg)

Molecular weight (kmole/kg)

Description

Mixing mass at arbitrary Location $(\mathrm{kg})$ 


\begin{tabular}{|c|c|}
\hline$m_{2}$ & Fuel Mass in zone\#2 (kg) \\
\hline$m_{2_{B}}$ & Fuel consumption in zone\#2 $(\mathrm{kg})$ \\
\hline$m_{2_{i}}$ & Loop iteration fuel vapor (kg) \\
\hline$N_{s}$ & Rotation Engine Velocity (rev/min) \\
\hline $\mathrm{P}$ & Pressure $(\mathrm{kPa})$ \\
\hline$m_{2_{\min }}$ & Amount of vapor at zone\#2 end $(\mathrm{kg})$ \\
\hline Pin & Intake Air Pressure (kPa) \\
\hline$P_{\text {in } j}$ & Injection Pressure $(\mathrm{kPa})$ \\
\hline$P_{\text {inj }}$ max $_{\text {nax }}$ & Maximum Injection Pressure (kPa) \\
\hline$P_{\text {inj } j_{\min }}$ & Minimum Injection Pressure (kPa) \\
\hline$Q_{\text {release }}$ & Heat Release (kJ) \\
\hline$Q_{\text {transfer }}$ & Heat Transfer $(\mathrm{kJ})$ \\
\hline$r_{L}$ & Spray Radius at Liquid Length (mm) \\
\hline$r_{s}$ & Spray Radius (mm) \\
\hline$R_{u}$ & General Gases Constant (kJ/kg.k) \\
\hline $\mathrm{t}$ & Spray Penetration Time (s) \\
\hline$T_{\text {air }}$ & Ambient Air Temperature (K) \\
\hline Tin & Intake Air Temperature (K) \\
\hline$T_{x}$ & Temperature of Zone\#2 at arbitrary Location (K) \\
\hline$\hat{t}$ & Non-dimensional Time Parameter \\
\hline$\hat{t}_{L}$ & Non-dimensional Time of liquid length \\
\hline$t^{+}$ & Time Scale Parameter \\
\hline$U_{\text {fuel }}$ & Fuel Velocity (m/s) \\
\hline$V_{1}$ & Volume in Zone\#1 $\left(\mathrm{m}^{3}\right)$ \\
\hline$V_{2}$ & Volume in Zon\#2 $\left(\mathrm{m}^{3}\right)$ \\
\hline$V_{3}$ & Volume in Zon\#3 $\left(\mathrm{m}^{3}\right)$ \\
\hline$V_{5}$ & Volume in Zon\#5 $\left(\mathrm{m}^{3}\right)$ \\
\hline $\mathrm{x}$ & Axial Spray Penetration Distance (mm) \\
\hline$\check{x}$ & Normalized Factor \\
\hline$x^{+}$ & Spray Penetration Length Scale \\
\hline
\end{tabular}

\section{Greek letters}

$\alpha_{1}, \beta_{1}$
$\rho_{a}$
$\rho_{f}$
$\hat{\rho}$
$\Phi$
$\theta$
$\theta_{g}$

Linear Regression Parameters

Air Density $\left(\mathrm{kg} / \mathrm{m}^{3}\right)$

Fuel Density $\left(\mathrm{kg} / \mathrm{m}^{3}\right)$

Density Ratio

Local Equivalence Ratio

Crank angle (degree)

Spray Angle (degree)

\section{$\underline{\text { Subscripts }}$}

$\begin{array}{ll}\text { EOI } & \text { End of Injection } \\ \text { SOI } & \text { Start of injection } \\ \text { TDC } & \text { Top Dead Center }\end{array}$




\section{INTRODUCTION}

For a long time, internal combustion engines have been the principal source of power in many industrial fields. Among them, the compression ignition combustion engine which has been widely used in vehicles and electric power generation. Reduction fuel consumption for compression ignition engine development is an important task as fuel cost is a major expense for many applications of that engine. An engine combustion simulation is one of the important tools for the compression ignition engine performance optimization design. The mathematical model can drastically reduce the number and prototypes of the experiment during the early design stages as well as contribute to the investigation of a wide control strategy number during the calibration phase of the engine. Nowadays, many internal combustion engines manufacture make extensive use of simulation codes, which can completely describe the engine behavior starting from the intake mouth up to the exhaust tailpipe (Darnfors and Johansson 2012, De Bellis, Severi et al. 2014, Zou, Xu et al. 2014, Zhang, $\mathrm{Xu}$ et al. 2016). The complex task of compression ignition engines, which have attained a higher degree of sophistication, can be achieved by compound advanced experiments and computational studies. In spite of the quantitative uncertainties of numerical simulations, which are often greater than those of experiments are, the modeling of combustion engine processes has some significant advantages that make its utilization in engine development a necessity (Raeie, Emami et al. 2014). Matlab /Simulink software is one of the most sufficient programs of simulation compression ignition combustion engine, which provides a flexible and modular tool for coupling engine cycle simulations with gasdynamic models (Higgins, Mueller et al.). For the processes that govern performance and emissions of the internal combustion engine, two basic types of models have been developed. These can be categorized as thermodynamic or fluid dynamic in nature, depending on whether the equations which give the model are based on energy conservation or a full analysis of the fluid motion. Oskam was investigated matlab simulation model for heat release by employing vibe parameters and the analysis of temperature - specific entropy techniques (Oskam 2014). Peng Qi, et al. were proposed quasi-dimensional model for compression ignition engine by applying matlab-simulink, based on the phase divided spray mixing model (Qi, Feng et al. 2010). Zweiri, was developed non-linear dynamic model of a generic four-stroke direct-injection single-cylinder diesel engine, for estimating engine parametric, by employing a novel numerical technique (Zweiri 2003). Ma, et al. were carried out quasi-dimensional multi-zone diesel combustion model, by using Musculus-Kattke model coupled with the CHEMKIN code (Ma, Tauzia et al. 2014).Bengtsson, et al. were achieved single cycle simulation model to predict the auto-ignition, the model was involved a lumped chemical kinetic model for hydrocarbon fuels (Bengtsson, Gafvert et al. 2004) .

Egüz was implemented the Flamelet Generated Manifold method (FGM) within the CFD framework, and applying the technique on diesel engine (Eguz 2013). The aim of present research is study the thermodynamic model of compression ignition combustion engine to describe the thermodynamic behaviours of combustion, injection, compression, and expansion processes by using Matlab platform.

\section{MATHMETICAL AND NUMERICAL MODEL}

Multi-zone model for direct injection compression combustion engines describe the mixture formation and combustion processes. Simulation model divides the combustion chamber into five zone; liquid fuel (zone\#1), vapor of fuel (zone\#2), rich premixed burn mixture (zone\#3), diffusion flame (zone\#4), and air bulk head (zone\#5). 
The mechanism of changing volume with the crank angle of cylinder consists from, connecting rod, piston, and head assembly is described as follows (Ferguson and Kirkpatrick 2015)

$$
V(\theta)=V c+\frac{\pi}{4} * B^{2} * l 1+a-\left[\left(l 1^{2}-a^{2} * \sin ^{2}(\theta)\right)^{\frac{1}{2}}+a * \cos (\theta)\right]
$$

\section{Injection theory}

Fuel velocity in model accounts as follows (Turns 1996);

$U_{\text {fuel }}=\frac{C_{d d}}{C_{a}} * \sqrt{\frac{2 *\left(P_{\text {inj }}-P\right) * 1000}{\rho_{f}}} \quad(\mathrm{~m} / \mathrm{s})$

Mass flow rate in kilogram per millisecond accounts as following (Siebers 1999) .

$$
\dot{m}_{f}=C_{a} * A_{\text {inj }} * \rho_{f} * U_{f u l l} \quad(\mathrm{~kg} / \mathrm{s})
$$

Mass flow rate in kilo mole per crank angle unite accounts as following (Turns 1996).

$\dot{m}_{C A}=\frac{\text { holess } \dot{m}_{f}}{0.006-N_{s}-M W_{f}} \quad$ (kmol/deg)

Injection duration in crank angle unit accounts as following (Turns 1996).

$d u r_{C A}=\frac{m_{f}}{\dot{m}_{C A}}$

Injection pressure $\boldsymbol{P}_{i n j}$ is assumed to be ramp pulse, during injection period, between maximum and minimum pressure injection. The pressure injection in every time step accounts as following relation (Asay 2003).

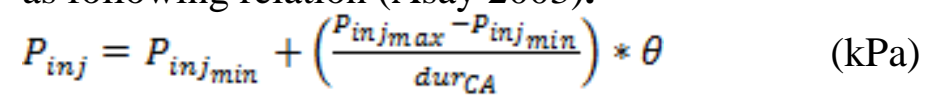

\section{Spray Spreading Angle}

The spreading angle of a diesel spray is considered a function of orifice geometry parameters (i.e., sharp versus smooth orifice edges, the aspect ratio, the orifice orientation) and the ratio of the fuel and the ambient gas densities (Reitz and Bracco 1979, Wu, Su et al. 1983, Varde, Popa et al. 1984, Hiroyasu and Arai 1990, Naber and Siebers 1996). Siebers, in (Siebers 1999) was described empirical correlation relationship to determine spray spreading angle from densities ratio.

$$
\tan \left(\frac{\theta_{s}}{2}\right)=c \cdot\left[\left(\frac{\rho_{a}}{\rho_{f}}\right)^{0.19}-0.0043 \sqrt{\frac{\rho_{f}}{\rho_{a}}}\right]
$$

\section{Axial Variation of the Fuel/Ambient-Gas Ratio}

In the derived of an axial variation of fuel/ ambient gas ratio relationship in spray a simplifying assumption is made. This assumption essentially implies that the droplets in the spray are small enough that they follow the gas flow, which means the spray has locally homogeneous flow(Higgins, Mueller et al. 1999, Siebers 1999).

$$
\begin{aligned}
& x^{+}=\sqrt{\frac{\rho_{f}}{\rho_{a}}} * \frac{\sqrt{c_{a}} * d}{\tan \left(\theta_{s / 2}\right)} \\
& \check{x}=\frac{x}{x^{+}} \\
& \phi=\frac{m_{f}(x)}{\dot{m}_{a}(x)}=\frac{2}{\sqrt{1+16 \cdot x^{2}-1}}
\end{aligned}
$$

\section{Liquid Length Scaling Law}

An empirical correlation function of liquid length was investigated by Higgins, and Siebers in (Higgins, Mueller et al. 1999) . Specific energy ratio $\boldsymbol{B}_{\boldsymbol{e}}$ in equation (15) is dependent parameter. The correlation take the form of power law as follow:

$B_{e}=\frac{c_{p_{\text {fuel }}} \cdot\left(T_{\text {boil }}-T_{f}\right)+h_{\text {vap }}}{c_{p_{\text {air }}} \cdot\left(T_{\text {air }}-T_{\text {boil }}\right)}$ 


$$
\begin{aligned}
& \widetilde{L}=b_{l} * \sqrt{\left[\frac{2}{B_{e}}\right]^{2}-1} \\
& \hat{\rho}=\frac{\rho_{f}}{\rho_{a}} \\
& L=k_{1} * d_{\text {orifice }} * \hat{\rho}^{\alpha_{1}} * B_{e} \beta_{1} \\
& t^{+}=\frac{x^{+}}{U_{\text {fuel }}} \\
& \hat{t}=\frac{t}{t^{+}} \\
& \hat{t}_{L}=\frac{\hat{L}}{2}+\frac{\hat{L}}{4} * \sqrt{1+16 * \widehat{L}^{2}}+\frac{1}{16} * \ln \left(4 * \widehat{L}+\sqrt{16+\widehat{L}^{2}}\right)
\end{aligned}
$$

\section{Combustion Calculations for Five Zones Model}

The volume of each zone can be determined from spray penetration. The mass of fuel in each zone can be calculated from (18). Mass of entrained air in each zone is obtained from multiplying the density in the cylinder by volume of each zone.

\section{Calculations of Zone\#1}

Zone\#1 is completely formed when the spray reaches the liquid length, zone\#1 is contains from liquid fuel and entrained air, the volume of zone\#1 depends on pressure and temperature in addition to injector properties. Mass and volume are determined as follows (Turns 1996, Asay 2003)

$$
\begin{array}{ll}
m_{f_{1}}=\dot{m}_{f} * t * M W_{f} & (\mathrm{~kg}) \\
V_{1}=\frac{\pi}{3} * r_{L}^{2} * L_{L} & \left(\mathrm{~m}^{3}\right) \\
m_{a_{1}}=\rho_{\text {air }} * V_{1} & (\mathrm{~kg})
\end{array}
$$

\section{Calculations of Energy in Zone\#1}

The temperature in zone\#1 is defined to be the boiling temperature of the fuel since the temperature is approximately constant during vaporization process of fuel. The enthalpy is calculated at the boiling temperature and the fuel injection temperature (Heywood 1988, Ferguson and Kirkpatrick 2015).

$$
E_{1}=m_{f_{1}} \times C_{p_{f}} \times\left(T_{\text {boil }}-T_{\text {inj }}\right)
$$

\section{Calculations of Zone\#2}

Once the liquid length is reached, zone\#2 begins to form, which comprises the rest of the fuel jet until the start of combustion. Mass and volume, from zone\#2 beginning until start of combustion or ignition delay time, are determined as follows (Heywood 1988, Ferguson and Kirkpatrick 2015).

$$
\begin{array}{ll}
V_{2}=\frac{\pi}{3} * r_{s}^{2} * L_{s}-V_{1} & \left(\mathrm{~m}^{3}\right) \\
m_{2}=\rho_{\text {air }} * V_{2} & (\mathrm{~kg}) \\
m_{f_{2}}=\dot{m}_{f} * t * M W_{f}-m_{f_{1}} & (\mathrm{~kg})
\end{array}
$$

\section{Calculations of Interference Region}

Once the ignition delay time begins, the fuel vapor begins to react, the reaction continues until approximately seventy-five percent of initial mass is consumed, reaction rate is determined by employing Arrhenius equation, Arrhenius theory was based on that the reactants to transform into products they must first acquire a minimum amount of activation energy, At an absolute temperature $\mathrm{T}$, the fraction of molecules that have a kinetic energy greater than active energy (Siebers 1999), (Turns 1996) .

Consumption of fuel rate in zone\#2 as follows

$$
m_{2_{\min }}=\frac{m_{f_{\text {mign }}}}{4}
$$

Where $\boldsymbol{m}_{\mathbf{z}_{\min }}$ amount of vapor at which lift-off is fully formed, $m_{2_{\tilde{f}}}$ is loop iteration fuel vapor, $\boldsymbol{m}_{f_{2 i g n}}$ is amount of vapour at ignition delay time (Asay 2003). 


$$
\begin{aligned}
& E a=\frac{B C}{(\operatorname{cotan}+25)} \\
& m_{2_{B}}=\Sigma-\left(m_{2_{\mathrm{i}}}-m_{2_{\text {min }}}\right) \times A_{p F} \times \exp \left(\frac{E_{a}}{R_{u}-T_{\text {boil }}}\right) \\
& m_{a_{G S T}}=m_{2_{B}} \times A F_{s}
\end{aligned}
$$

\section{Energy Calculations in Zone\#2 and Interference Region}

Energy in interference region and zon\#2 is determined by applying energy balance principle on the control volume as shown in figure (a). Since the entering enthalpy equals the existed enthalpy as following equation (Asay 2003).

$H_{x}=H_{\text {fuel }}+H_{\text {air }}+H_{\text {prod }}$

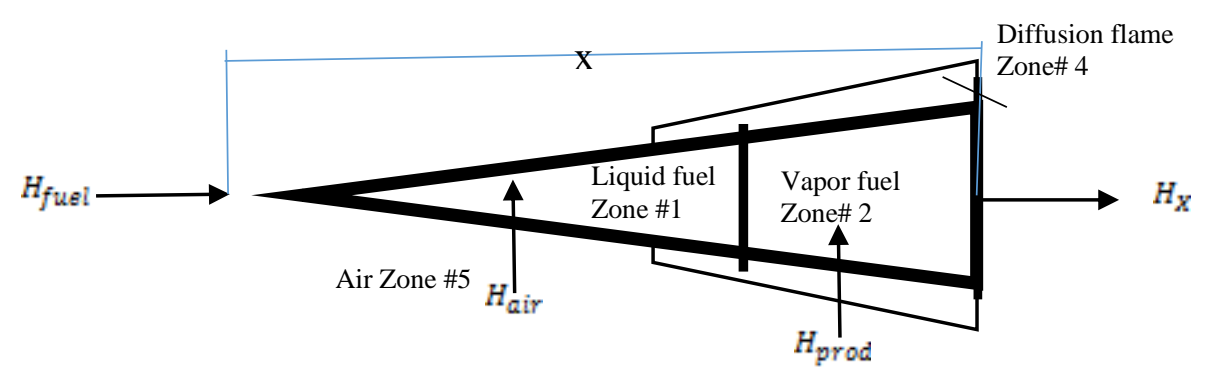

Fig. (a) : Heat Balance Process

$\boldsymbol{T}_{\boldsymbol{x}}$ is temperature of zone\#2 at each location $(\boldsymbol{x})$ of the spray between steps. This temperature and the overall composition are used to calculate the total enthalpy in the zone (Asay 2003).

$T_{x}=\frac{m_{\text {fuel }} \cdot\left(c_{p, f u e l} * T_{\text {boil }}-h_{f g}\right)+m_{\text {air }} \cdot c_{p, \text { air }}-T_{\text {aîr }}+m_{\text {prod }} \cdot C_{p, p r o d}-T_{\text {prod }}}{m_{x} \cdot C_{P, x}}$

$E_{2}=\frac{m_{5 a}-h_{5 a}}{M W_{a}}+\frac{m_{\text {prod }}-h_{4}}{M W_{4}}+m_{f \text { wel }} \times c p_{f} \times\left(\frac{T_{x}-m_{x}}{\left(m_{a_{S T}}+m_{u f_{x}}+m_{\text {prod }}\right)}-T_{\text {boil }}\right)$

\section{Calculations of Zone\#3}

Zone\#3 begins to form at start of combustion. While zone\#2 is reducing, zone\#3 grows toward the injector and outward with the spray tip. When zone\#2 reaches its minimum, zone\#3 grows only toward the spray tip as penetration continues. This zone is formed from products of combustion. Zone\#3 forms products gases and fuel vapor, volume and mass are determined as follows (Heywood 1988, Ferguson and Kirkpatrick 2015).

$$
\begin{aligned}
& V_{3}=\frac{\pi}{3} \times r_{s}^{2} \times L_{s}-V_{s r} \\
& m_{f_{\mathrm{s}}}=M W_{f} \times \dot{m}_{f}\left(t-t_{l f t}\right)+m_{u f_{\mathrm{n}}} \\
& m_{3 p r o d}=m_{f_{\mathrm{s}}}+m_{f_{\mathrm{s}}} / A F_{3}
\end{aligned}
$$

\section{Energy Calculations in Zone\#3}

The enthalpy, temperature, and the products compositions in zone\#3 are determined using adiabatic flame temperature and equilibrium models. The adiabatic Flame temperature is found by an iterative approach using secant method (Heywood 1988, Ferguson and Kirkpatrick 2015).

$$
E_{3}=\frac{m_{\text {sprod }} h_{p g}}{M W_{p s}}
$$

\section{Calculations of zone\#4}

Zone\#4 develops at the start of combustion. Zone\#4 is representing the diffusion flame sheath surrounding the spray. Zone\#4 is characterized by the adiabatic flame temperature that is produced on the boundary between the fuel rich jet (zones\#2 and zones\#3) and the surrounding air (zone\#5) adiabatic flame temperature is found as follows (Asay 2003).

$T_{i+1}=T_{i}+\frac{h_{p}-h_{r}}{(d h / d T)}$ 


\section{Calculations of Zone\#5}

Zone\#5 is the air, which is surrounding bulk head. Zone\#5 mass is calculated by subtracting the mass of air entrained in the spray from the total air mass in the cylinder (Heywood 1988, Ferguson and Kirkpatrick 2015).

$m_{5_{a}}=\frac{p \cdot V}{R_{u} \cdot T_{\text {in }}} \times M W_{a}-\left(m_{1}+m_{2}+m_{3}\right)$

\section{Internal Energy Calculations in Zone\#5}

The internal energy in zone\#5 calculates by subtracting the internal energy in the zone\#1, zone\#2, and zone\#3 from the total cylinder internal energy (Heywood 1988, Asay 2003, Ferguson and Kirkpatrick 2015).

$h_{a_{a_{i}}}=\sum_{i} x_{5_{i}} \times h_{5_{i}}(T)$

$m_{f_{t}}=m_{f_{1}}+m_{f_{z}}+m_{f_{\mathrm{s}}}$

$U_{5}=\frac{m_{s_{a}} \cdot h_{a_{5}}}{M W_{a}}-P \times V-P\left(V_{2}-V_{1}\right)+Q_{\text {release }}-Q_{\text {transfer }}+\frac{m_{f t} f_{f u e l}^{-h_{f u}}}{M W_{f}}$

$E_{5}=U_{5}-\left(E_{1}+E_{2}+E_{3}\right)+P \times V$

The energy in zone\#5 is used to find the temperature $\boldsymbol{T}$ in zone\#5, using an iterative method with the enthalpy curve fits.

\section{Pressure Calculations}

All zones are of equal pressure but differing temperature (Dec 1997). Pressure is determined by applying equation of state for ideal gas as follows .

$$
P=\frac{\left(\frac{m_{\text {air }}}{M W_{a}}+\frac{m_{\text {products }}}{M W_{p}}+\frac{m_{\text {fueI }}}{M W_{f}}\right)-R_{u}-T}{V}
$$

\section{MATLAB MODEL}

The mathematical formulation of the model has been coded in the Matlab platform as shown in figure (18). The main model forms sub-models, perform the function in the model. The sub-models are programmed in script language in Matlab platform, the structure of the mathematical model consists of:

Isentropic Sub-Model, which simulates the isentropic compression and expansion of piston in the cylinder. The model calculates the volume in every step, equals 0.25 of crank angle degree as described in Eq.(1) the thermodynamic properties of the cylinder, in piston movement according to the isentropic relation is as follows:.

Injection Sub-Model, which is to simulate the fuel injection process, and the association process such as combustion, fuel vaporizing, heat release, heat transfer. This model is considered the most important model and it involves several sub-models; spray penetration, injector, fuel properties, adiabatic flame temperature, heat release, premixed burn, heat transfer, and ignition delay. The algorithm of determining spray penetration is shown in figure (19)

\section{RESULTS AND DISSECTION}

The results of penetration jet, which are obtained from the MATLAB model and employing scaling law (Ferguson and Kirkpatrick 2015), are shown in figures (1) and (2). Figure (1) shows the spray penetration jet dimensions; radius, length, spread spray angle and various combustion regions. The first one, the region (S1-S2) refers to the start of injection and mixing liquid fuel with air. This region represents the full form of liquid fuel length, which is referred to as zone\#1 in this research. The second region (S2-S3) indicates the start of fuel vaporization and mixing the vapor fuel droplets with air. The region (S2-S3) represents zone\#2 in this research. After that, there's an interference region between zone\# 2 and zone\#3. The interference starts at location S3 and ends at location S4. At location S3 the combustion is started, which is regarded as a location of commencement zon\#3 and 
contraction of zone\#2. The region (S1-S3) refers to ignition delay. At the interference between zone\#2 and zone\#3, the mass of vapor fuel begins to contract until it reaches its minimum value at the location S4. At location S3, when combustion is started, air and product entrain to the combustion zone. When spray penetration jet reaches location S4 rich product burn is started. After that, the only products entrains to the combustion zone. After location S3 the entrained air is decreased while the products are increased until spray is reached the location S4 when zone\#2 disappeared completely and spray is reached lift-off flame length. Due to combustion, the equivalence ratio decreases, at location S5, the equivalence ratio equal to one (stoichiometric combustion). After that, the equivalence ratio is decreased (rich products). The location S6 represents the end of injection (EOI). The development stages of spray penetration jet with crank angle variant during the period of injection as described in figure (2). Figure (3) illustrates the effects of engine speed on spray penetration zones. It's clearly shown that there's an enlargement in the premixed burn region (zone\#3) with increasing engine speed at the prescribed rate of fuel, intake air pressure and temperature. Here, the convenient values of engine speed are chosen as 1300 RPM and1500 RPM. Also, the values of the mass flow rate of fuel, the intake air pressure and temperature are 0.002876 $\mathrm{kg} /$ cycle, $250 \mathrm{kPa}$, and $400 \mathrm{~K}$ respectively. To that, the simulation can be chosen as the optimum start of injection for maximum energy per cycle. Figure (4) shows the effects of intake air pressure on spray penetration jet at specified engine speed, and fuel mass flow rate. Here the optimum start of injection can be obtained for the maximum energy/cycle. Also from the figure can be shown an enlargement in the premixed burn region (zone\#3) with increasing intake air pressure. Figure (5) clarifies the effects of intake air temperature on spray penetration jet at fuel mass flow rate, engine speed. From the figure, can be seen that there's a change in the stoichiometric combustion location (S5) towards the end of injection (S6) with an increase in intake air temperature. Also, can be concluded that with an increase in intake air temperature there's no effect in rich products premixed region (zone\#3), whilst there slightly increases in the length of penetration spray. Figure (6) shows the variation of penetration length with SOI at the same engine speed, fuel mass flow rate, orifice diameter, number of holes, intake air pressure and temperature. Figure (7) shows the effect of several orifice holes on the spray penetration jet. The figure indicates the decreasing of injection duration at same engine speed, fuel mass flow rate, orifice diameter, intake air pressure and temperature as a result of increasing numbers of holes. In the case of 6 holes, the maximum energy is greater than 5 holes. Figure (8) show fuel liquid length and entrained air in zone\#1. The development of fuel liquid length starts at SOI and proceeds to form until it reaches fully form at initiates of zone\#2. After that both liquid fuel and entrained air remain constant, tile completely consumed at the end of injection. Figure (9) show mass flow rate and entrained air mass for spray penetration jet, and in zone\#2. This zone is started from the start of vaporizing to the start of combustion. In this region vaporization, fuel and mixing with air represent the region between S2 and S3 it can be seen clearly the increasing in vaporization of fuel and slightly increase in entrained air. Figure (5.11) shows the energy in this region. It represents the heat of vaporization of the fuel, which is in a negative value. In this region no heat release takes place. Figure (10) shows zone\#2 shrinking as a result of burning fuel vapor droplets when it enthalpies are exceeded the active energy after ignition delay" the region between S3 and S4 in figure (1)". In this region, zone\#3 begins to form when both the entrained air and gas products are mixed with fuel vapor in spray jet. The products of combustion at this region are shown in figure (12). From figures $(10,12)$ obviously can be seen that the entrained air increasing at the beginning and then decreasing due to the formation of the product. Figure (11) shows that there's an effect in the premixed burn region with a change in fuel mass flow rate, engine speed, intake air pressure, and temperature. The increase in the premixed burn region leads to increase energy. Also, the start of injection affects the energy in the premixed 
burn region. In each fuel mass flow rate at specified engine speed, intake air pressure and temperature there is the optimum start of injection (SOI), which is given maximum energy per cycle. Figure (13) shows the mass flow rate of fuel, gasses products mass and mass of air consumption during the rich premixed burn. From this figure, it's noticed a reduction in the amount of mass of fuel and air, while the products of gases is decreased for each step, but the accumulative of the products of gases is increased in the whole process as shown in figure (14). Figure (15) shows the variation of equivalence ratio concerning crank angle in zone\#3 after lift-off flame during premixed burn" beyond interference region. Figures (16) and (17) show the pressure and temperature distribution for different fuel mass flow rate, and different optimum SOI with constant engine speed $=1500 \mathrm{RPM}$, intake air pressure $=250 \mathrm{kPa}$, and temperature $=450 \mathrm{~K}$. from the figures the maximum cylinder energy have the same peak pressure and temperature location at specified engine speed, intake air pressure, and temperature. That indicates the effect of SOI on maximum cylinder energy. The results of the simulation model for pressure and temperature distribution with crank angle are similar to the results and trend behavior in many published researches such as (Hiroyasu and Arai 1990, Naber and Siebers 1996) .

\section{Compassion with Other Methods}

The results of liquid when compare with measured results, which were measured in sandia national laboratories, in (Siebers 1998) indicate that, at fuel type DF2 and nozzle diameter equal to $0.246 \mathrm{~mm}$ the liquid length in model is greater than the measured data about $2.65 \%$ when $\rho_{a}=30.2$, and $4.32 \%$ when $\rho_{a}=14.8$, and $11.2 \%$ when $\rho_{a}=7.3$. The results of maximum pressure in cylinder indicate different about $1.2 \%$ from which that found by using the (FGM) method within CFD framework in (Eguz 2013).

\section{CONCLUSIONS}

The compression ignition engine simulation model produced for this work provides a framework for a more accurate zero-dimensional model by providing physical zones within the model that match to structures within a direct injection compression ignition engine. The approximate of modeling combustion of direct injection compression ignition engines through a mixing limited jet and determining the mixing limit through an empirical correlation of jet penetration showed promise. Comparison the results of the simulation model with published citation indicates agreement the behavior of thermodynamic specification with theoretically and experimentally previous works. The thermodynamic model results concluded changing of combustion zones with engine speed, amount of injected fuel, intake air pressure, and temperature, especially rich premixed burn zone. Rich premixed zone increased with intake air increasing these parameters. 


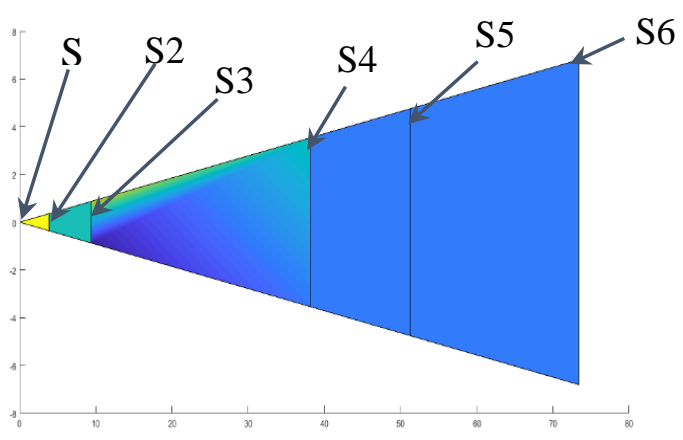

Fig. (1): Spray Penetration Cone

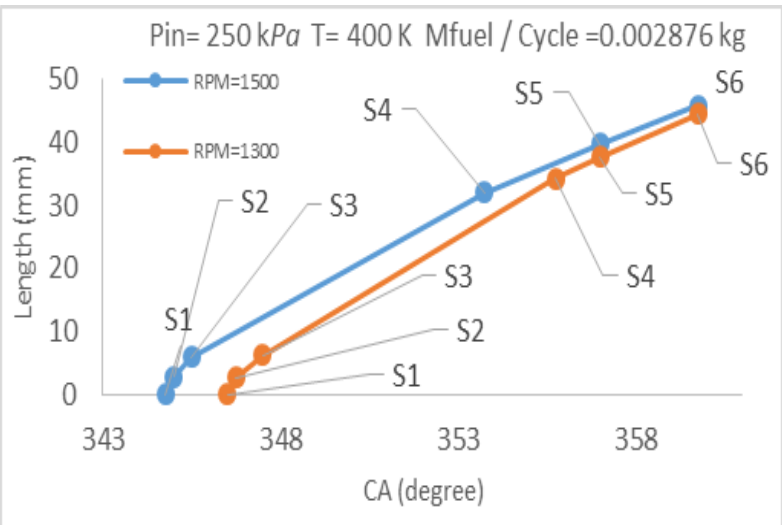

Fig. (3): Spray Penetration Jet Versus Crank Angle at Different Engine Speed

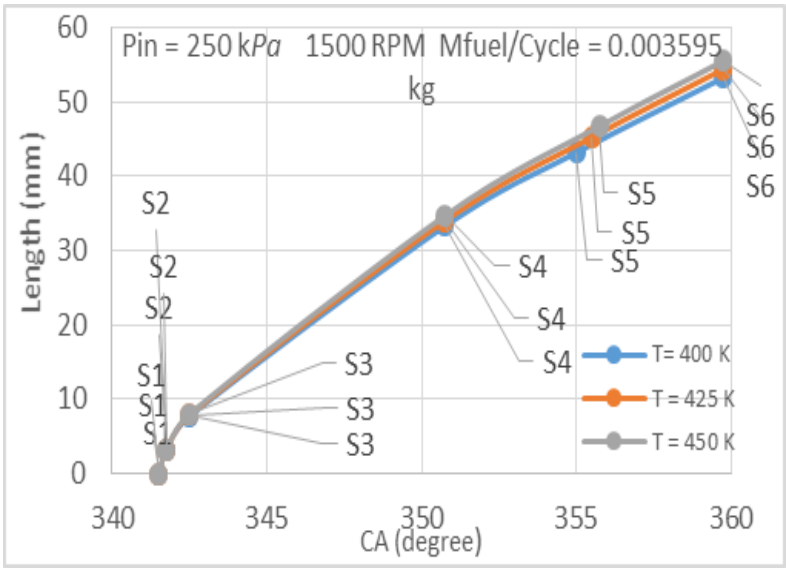

Fig. (5) : Spray Penetration Jet Versus crank Angle

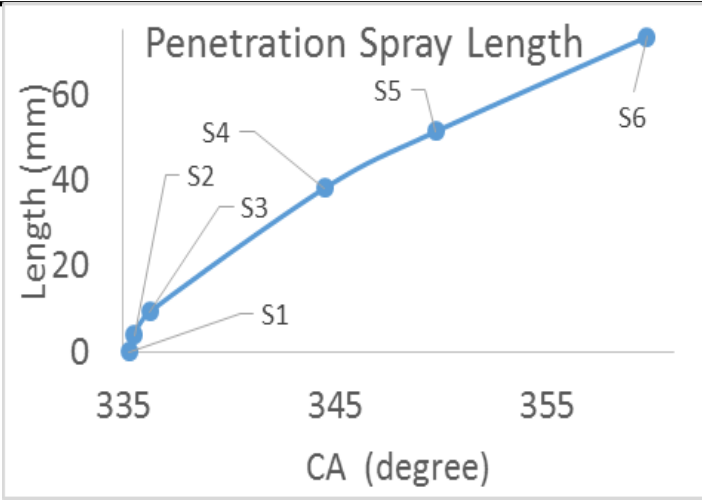

Fig. (2) : Spray Penetration Jet Versus Crank Angle

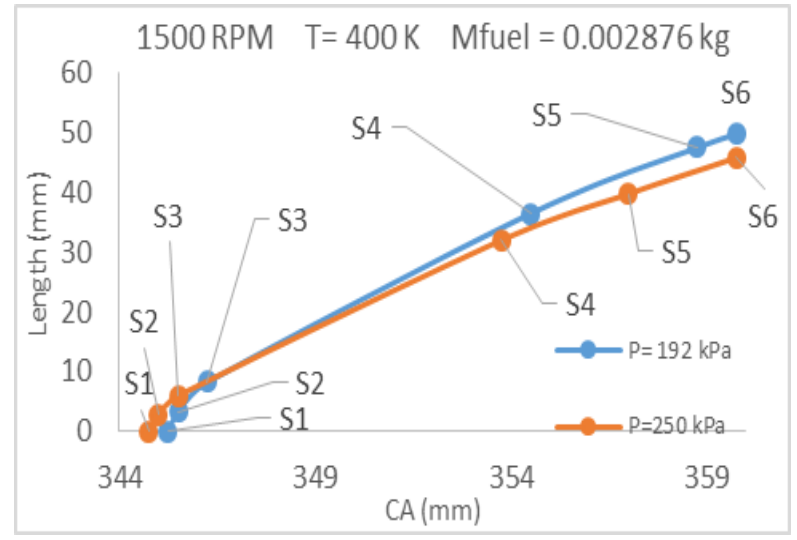

Fig. (4): Spray Penetration Jet Versus Crank Angle at Different Intake Air Pressure

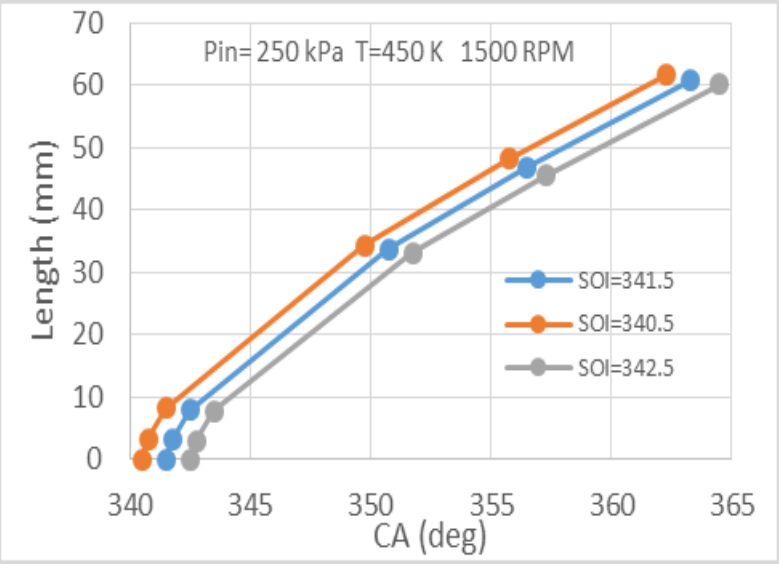

Fig. (6) : Spray Penetration Jet Versus Crank Angle 


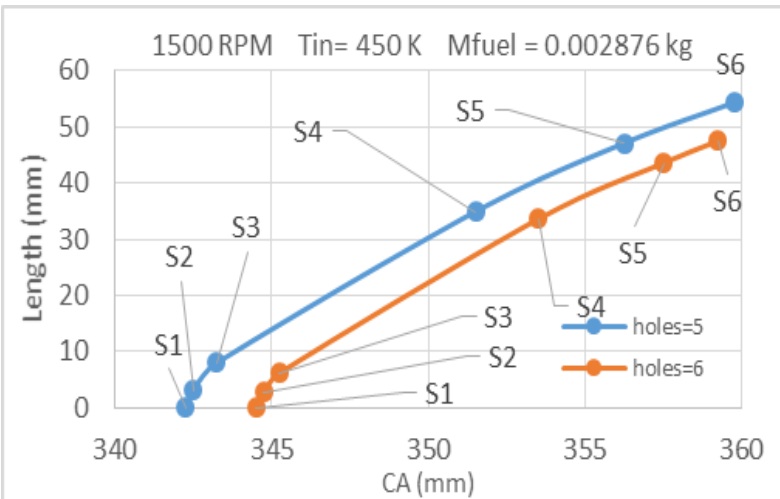

Fig. (7): Spray Penetration Jet Versus

Crank Angle at Different Numbers of holes

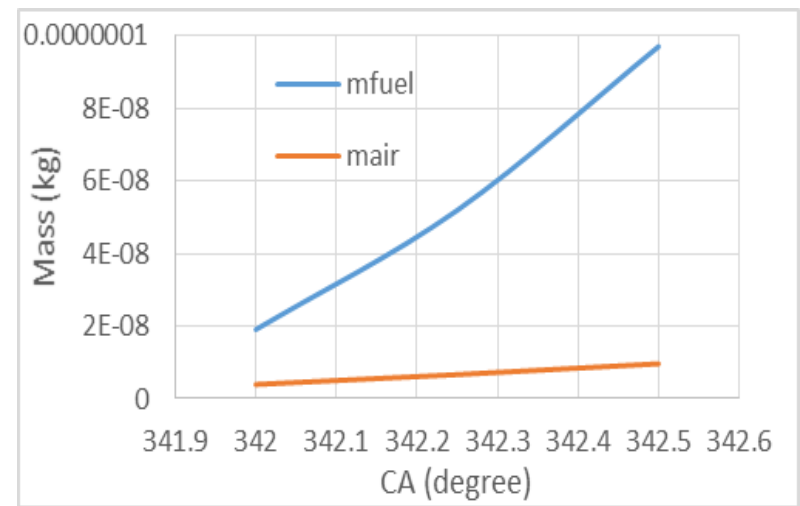

Fig. (9) : Fuel Mass Flow Rate and Entrained Air Development in Zone\#2

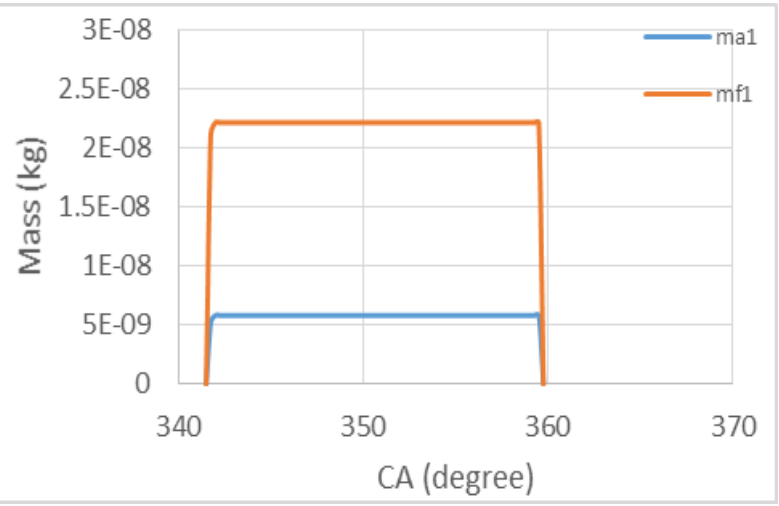

Fig.(8): Fuel Liquid Length and Entrained Air versus Crank Angle in Zone\#1

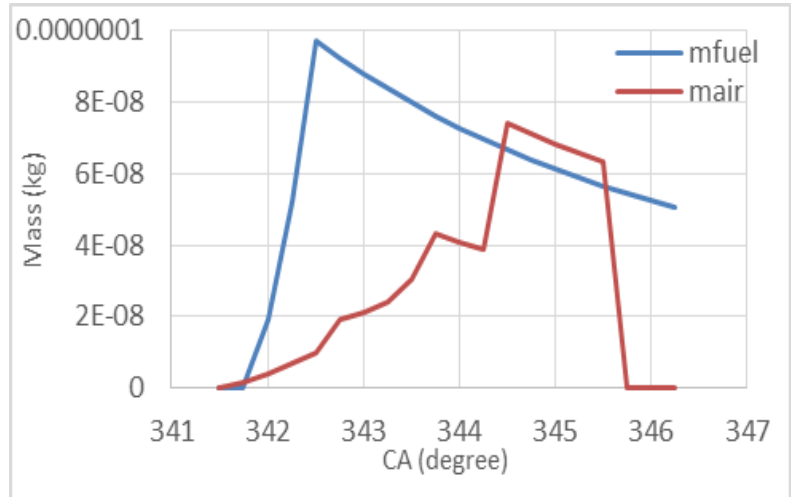

Fig. (10): Fuel Mass Flow Rate and Entrained Air Development in Interference
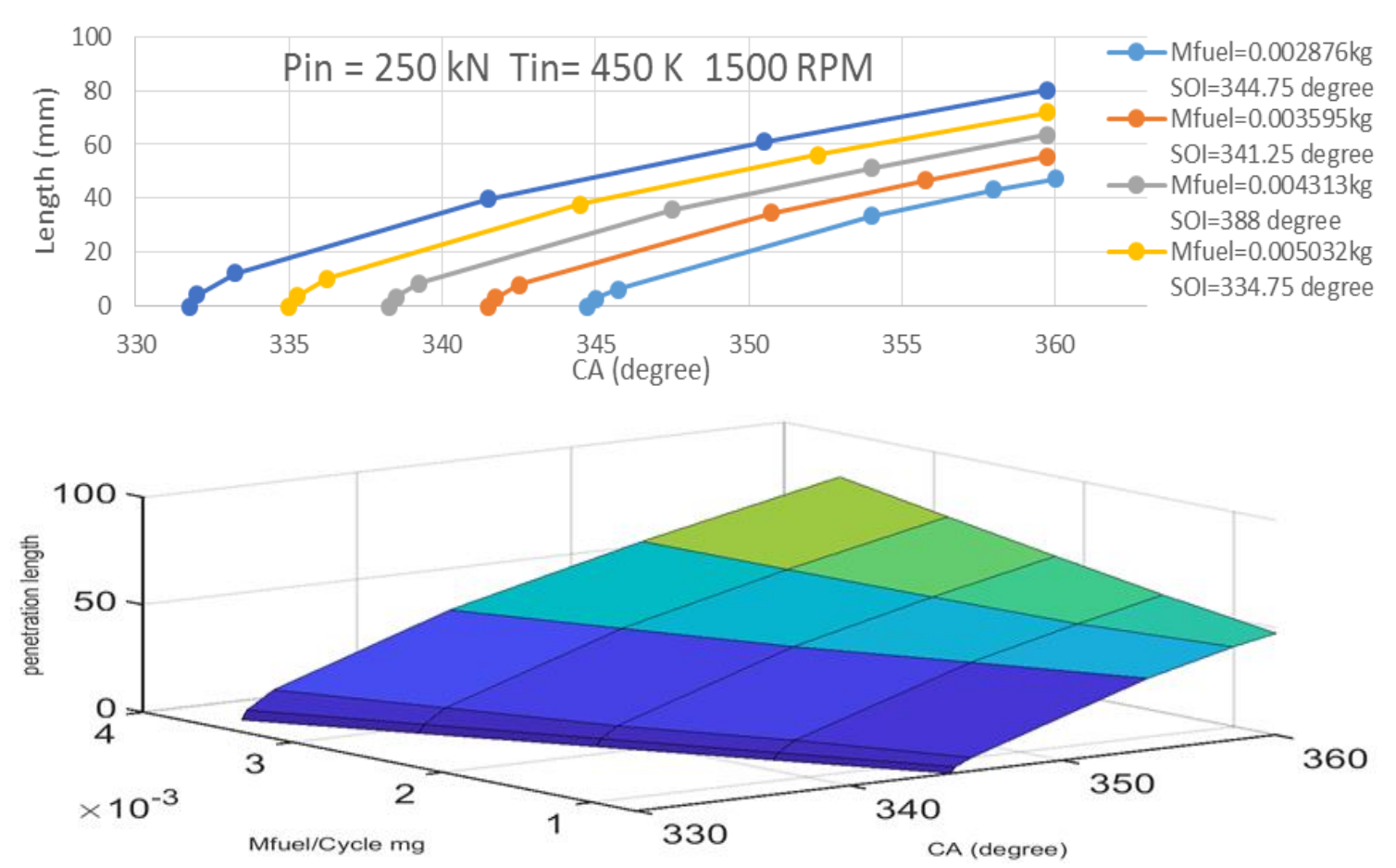

Fig. (11) : Spray Penetration Jet Versus Crank Angle at Different Fuel Mass Flow Rate and Different Optimum SOI 


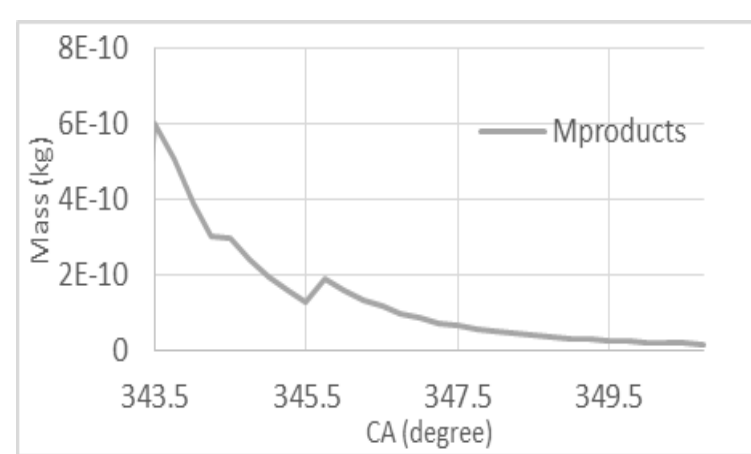

Fig. (12) : Products Mass Development in Interference Region

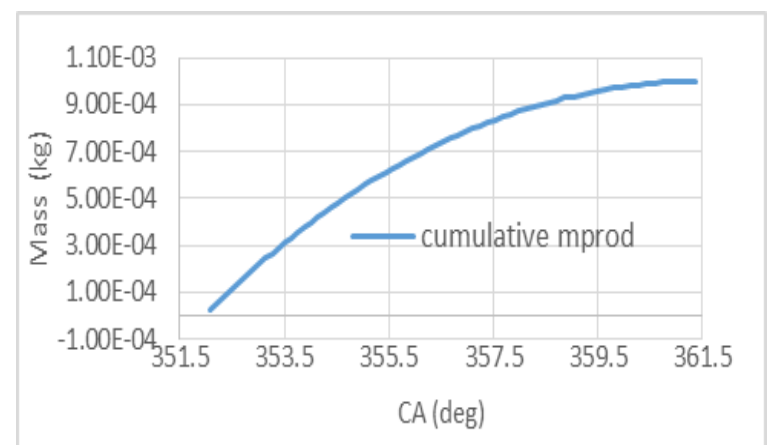

Fig. (14) : cumulative products mass development in zone\#3 beyond interference region

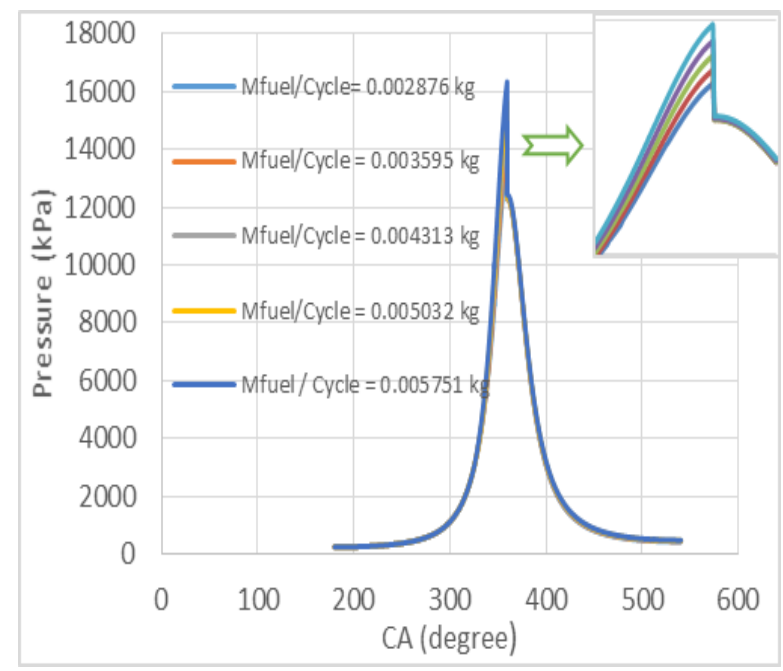

Fig. (16): Pressure Distribution Versus Crank Angle

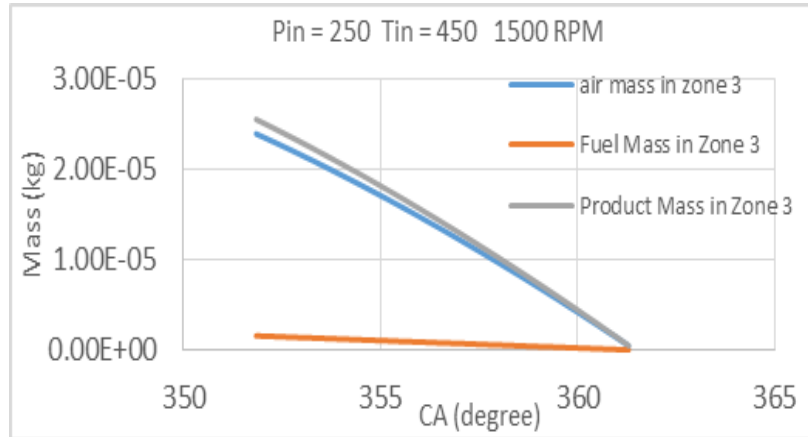

Fig. (13) : Fuel Mass Flow Rate, Entrained Air Mass , and Products Mass Development in Zone\#3

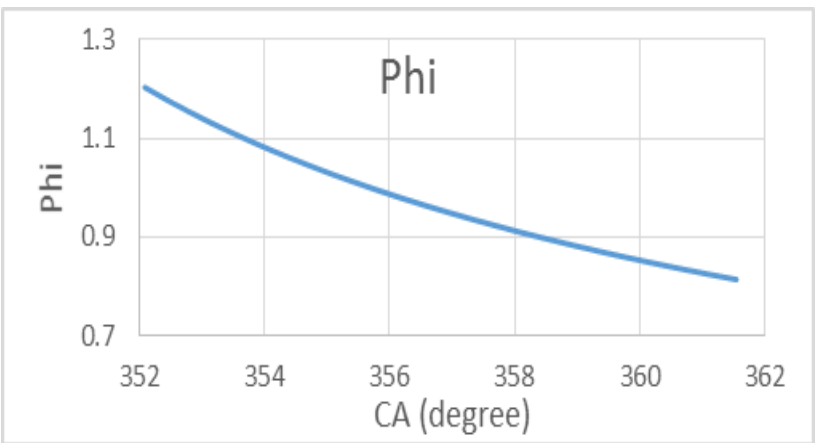

Fig. (15) : Equivalence Ratio in Zone\#3 Beyond Interference Region

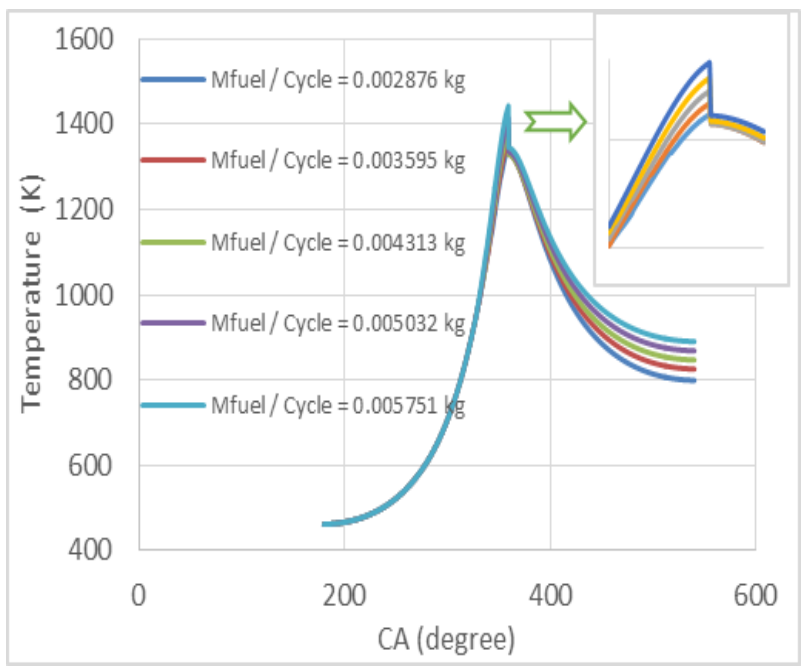

Fig. (17): Temperature Distribution Versus Crank Angle 


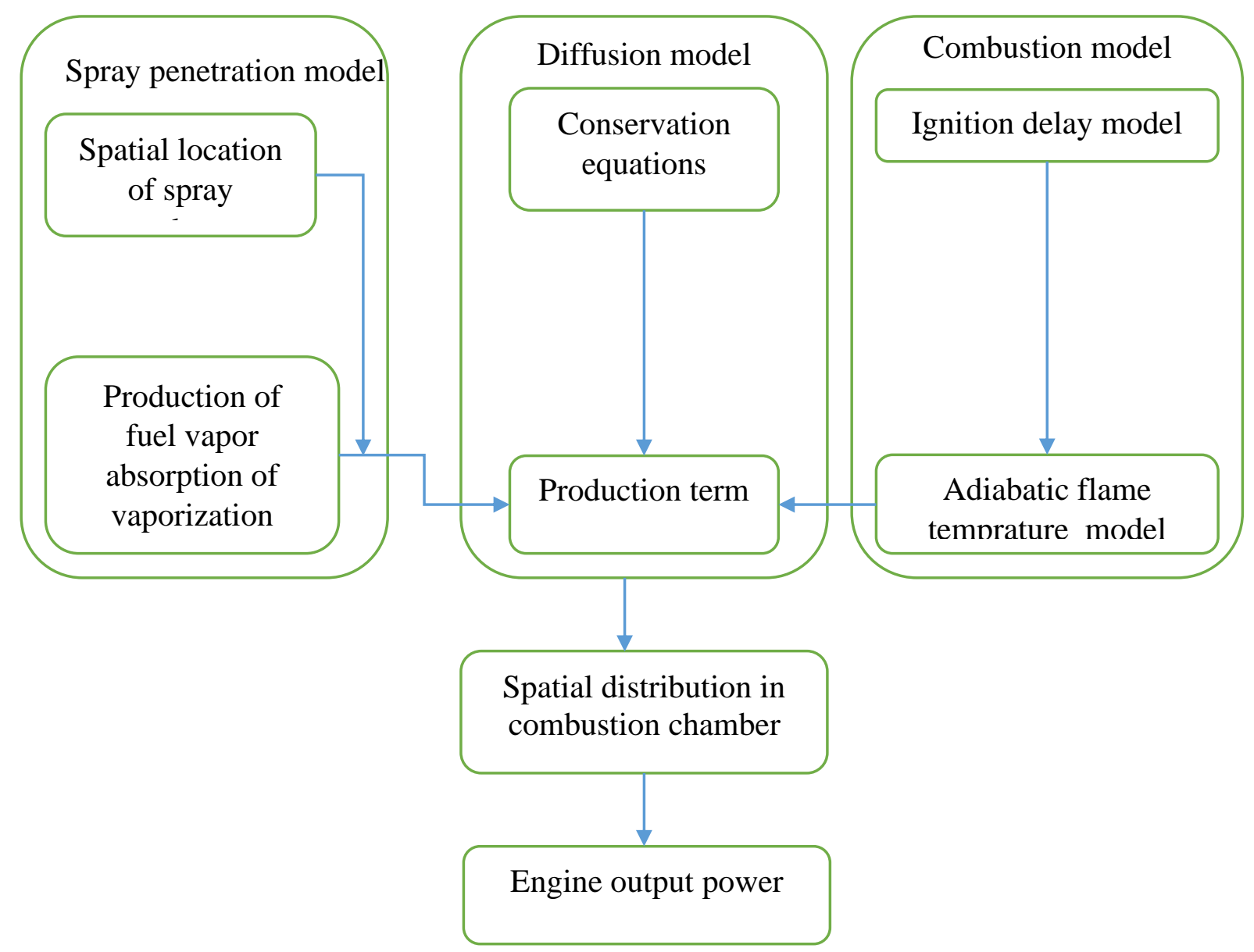

Fig. (18) : Algorithm of Main Model 


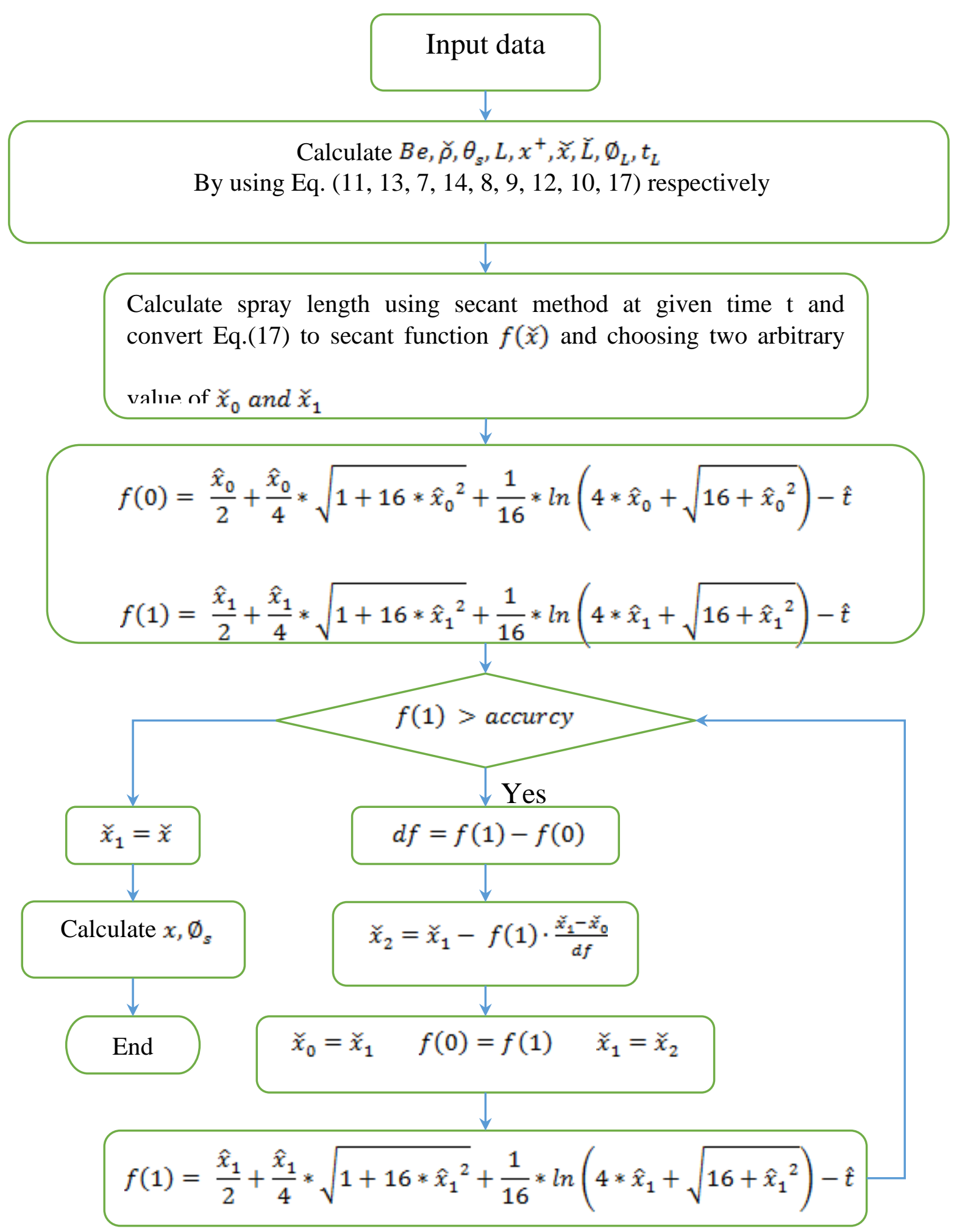

Fig. (19) : Algorithm of Penetration Spray Length 


\section{REFERENCES}

Asay, R. (2003). "A five-zone model for direct injection diesel combustion."

Bengtsson, J., et al. (2004). Modeling of HCCI engine combustion for control analysis. 2004 43rd IEEE Conference on Decision and Control (CDC)(IEEE Cat. No. 04CH37601), IEEE.

Darnfors, P. and A. Johansson (2012). Computationally Efficient Model for On-Board Simulation of Heavy Duty Diesel Engines.

De Bellis, V., et al. (2014). "Hierarchical 1D/3D approach for the development of a turbulent combustion model applied to a VVA turbocharged engine. Part II: combustion model." Energy Procedia 45: 1027-1036.

Dec, J. E. (1997). "A conceptual model of Dl Diesel combustion based on laser-sheet imaging." SAE transactions: 1319-1348.

Eguz, U. (2013). "Crossing the combustion modes in diesel engines."

Ferguson, C. R. and A. T. Kirkpatrick (2015). Internal combustion engines: applied thermosciences, John Wiley \& Sons.

Heywood, J. B. (1988). "Internal combustion engine fundamentals."

Higgins, B. S., et al. (1999). "Measurements of Fuel Effects on Liquid-Phase Penetration in Dl Sprays." SAE transactions: 630-643.

Hiroyasu, H. and M. Arai (1990). "Structures of fuel sprays in diesel engines." $\underline{\text { SAE }}$ transactions: $1050-1061$.

Ma, G., et al. (2014). "One-dimensional combustion model with detailed chemistry for transient diesel sprays." Proceedings of the Institution of Mechanical Engineers, Part D: Journal of Automobile Engineering 228(4): 457-476.

Naber, J. D. and D. L. Siebers (1996). "Effects of gas density and vaporization on penetration and dispersion of diesel sprays." SAE transactions: 82-111.

Oskam, G. (2014). "Optimizing diesel engine condition monitoring: Research on diagnostic representation techniques based on in-cylinder pressure measurement."

Qi, K.-p., et al. (2010). "Simulation of quasi-dimensional model for diesel engine working process." Journal of Central South University of Technology 17(4): 868-872. 
Raeie, N., et al. (2014). "Effects of injection timing, before and after top dead center on the propulsion and power in a diesel engine." Propulsion and power research 3(2): 59-67.

Reitz, R. D. and F. Bracco (1979). On the dependence of spray angle and other spray parameters on nozzle design and operating conditions, SAE technical paper.

Siebers, D. L. (1998). "Liquid-phase fuel penetration in diesel sprays." SAE transactions: 1205-1227.

Siebers, D. L. (1999). "Scaling liquid-phase fuel penetration in diesel sprays based on mixinglimited vaporization." SAE Transactions: 703-728.

Turns, S. R. (1996). An introduction to combustion, McGraw-Hill New York.

Varde, K., et al. (1984). "Spray angle and atomization in diesel sprays." $\underline{\text { SAE transactions: }}$ 779-787.

Wu, K.-J., et al. (1983). "Measurements of the spray angle of atomizing jets." Journal of fluids engineering 105(4): 406-413.

Zhang, K., et al. (2016). "Phenomenological two-phase multi-zone combustion model for direct-injection diesel engines." International Journal of Automotive Technology 17(5): 895907.

Zou, T.-a., et al. (2014). "Mathematical modeling and analysis of thermodynamic processes in a twin-rotor piston engine." Journal of Central South University 21(11): 4163-4171.

Zweiri, Y. H. (2003). Non-linear modelling and estimation for diesel engines, University of London. 